\title{
Prevalence and risk factors of peripheral artery disease in black Africans with HIV infection: a cross-sectional hospital-based study
}

This article was published in the following Dove Press journal: Vascular Health and Risk Management

\author{
Félicité Kamdem ${ }^{1,2}$ \\ Yacouba Mapoure ${ }^{1,2}$ \\ Ba Hamadou ${ }^{3}$ \\ Fanny Souksouna ${ }^{2}$ \\ Marie Solange Doualla ${ }^{1,3}$ \\ Ahmadou Musa Jingi ${ }^{3}$ \\ Caroline Kenmegne ${ }^{1}$ \\ Fernando Kemta Lekpa ${ }^{1,4}$ \\ Jaff Kweban Fenkeu' \\ Gisèle Imandy ${ }^{5}$ \\ Jean Pierre Nda Mefo'o ${ }^{2,5}$ \\ Henry Luma ${ }^{1,3}$ \\ 'Internal Medicine Service, \\ Douala General Hospital, Douala, \\ Cameroon; ${ }^{2}$ Faculty of Medicine and \\ Pharmaceutical Sciences, University \\ of Douala, Douala, Cameroon; \\ ${ }^{3}$ Department of Internal Medicine \\ and Specialties, Faculty of Medicine \\ and Biomedical Sciences, University \\ of Yaounde I, Yaounde, Cameroon; \\ ${ }^{4}$ Faculty of Health Sciences, University \\ of Buea, Buea, Cameroon; ${ }^{5}$ Chemical \\ Pathology Laboratory, Douala General \\ Hospital, Douala, Cameroon
}

Correspondence: Ahmadou Musa Jingi Department of Internal Medicine and Specialties, Faculty of Medicine and Biomedical Sciences, University of Yaounde I, Yaounde, PO Box I0I02, $\mathrm{CMH}$ Rue Hippodrome, Yaounde, Cameroon

Tel +237 677864833

Email jingiahmadoumusa@yahoo.co.uk
Background: The prevalence of peripheral artery disease (PAD) is not well known among HIV-infected patients in Africa. The aim of this study was to determine the prevalence and associated risk factors of PAD among HIV-infected patients at the Douala General Hospital (DGH). Methods: This was a cross-sectional descriptive and analytic study between November 2015 and April 2016. We recruited patients aged $\geq 21$ years, diagnosed with HIV infection, and who were receiving care at the DGH. We collected sociodemographic data and past medical history of patients. We measured their ankle-brachial index (ABI). We defined PAD as an ABI <0.9. We also measured their fasting blood glucose and lipid profile.

Results: We recruited 144 patients for this study. The mean age was $46 \pm 9$ years, and $72.2 \%$ were females. Of which, $89 \%$ were on antiretroviral treatment (ARV). Their mean CD4+ T lymphocytes count was $451 \pm 306$ cells $/ \mathrm{mm}^{3}$. Their mean ABI was $1.12 \pm 0.17$ and $1.07 \pm 0.11$, respectively, on the left and right legs $(P>0.05)$. The prevalence of PAD was $6.9 \%(95 \% \mathrm{CI}$ : 3.4-12.4), and $60 \%$ of patients with PAD were symptomatic. After adjusting for age, sex and ARV, ARV treatment was protective (aOR: 0.18, [95\% CI: 0.04-0.82], $P=0.034$ ), while WHO stages III or IV was associated with PAD (aOR: 11.1, [95\% CI: 2.19-55.92], $P=0.004$ ).

Conclusion: The prevalence of PAD was not as high as expected in this group of patients with high cardiovascular risk infected with HIV. Advanced HIV disease was associated with PAD, while ARV was protective.

Keywords: HIV, peripheral artery disease, prevalence, risk factors, Africa

\section{Introduction}

Cardiovascular diseases (CVDs) are the leading cause of death and disability in the world. ${ }^{1}$ Unlike stroke and ischemic heart disease, studies on peripheral artery disease (PAD) are rare in sub-Saharan Africa. ${ }^{2}$ In 2007, the High Authority for Health (HAS) defined the PAD as a narrowing of the caliber of the arteries that irrigate the lower limbs, resulting in a drop in the ankle-brachial index (ABI). ${ }^{3}$

Disability and mortality from PAD have increased over the past 20 years, with the greatest burden on women. ${ }^{4}$ Atherosclerotic CVD is also an increasing concern for the progressively aging HIV-infected population. This is likely a consequence of both traditional and nontraditional risk factors such as immune activation and inflammation that may contribute to an accelerated aging process, characterized by higher than anticipated rates of noninfectious comorbidities. ${ }^{5}$

The greatest burden of HIV infection, a global public health problem, is in lowincome settings. In 2013, sub-Saharan Africa accounted for almost 70\% of the new infections worldwide. ${ }^{6}$ In Cameroon, the prevalence of HIV infection was estimated 
at $4.8 \%{ }^{7}$ This infection was fatal until 1996, after which the use of anti-retroviral combination therapy (ARV) extended the life expectancy of those infected.

There are many risk factors for PAD in patients with HIV. These include: the HIV infection itself; increased aging process in infected individuals; adverse effects of ARV; and increased occurrence of diabetes and dyslipidemia. ${ }^{5,8} \mathrm{ABI}$ is a simple, cost-effective and validated method to assess PAD. ${ }^{3}$ It is the ratio of the systolic arterial pressure measured at the ankles to that measured at the arms (brachial artery). An ABI $<0.9$ is indicative of PAD. ${ }^{3}$ Data on PAD are generally sparse in this setting. There is a need to study PAD in HIV-infected patients known to possess increased risk factors for CVD. In view of this, we aimed at assessing the prevalence and risk factors of PAD in a group of patients infected with HIV infection in Cameroon.

\section{Methods}

\section{Study design and setting}

This was a cross-sectional descriptive and analytic study was carried out in the HIV Treatment Accredited Center (HTC) of the DGH from November 1, 2015 to April 30, 2016. The DGH is a tertiary health institution located in Douala-the economic capital of Cameroon. It has a catchment population of about 3.3 million inhabitants. ${ }^{9}$

\section{Participants}

Consecutive patients attending the HTC were approached for participation in this study. Adults of both sexes, aged $\geq 21$ years, HIV positive, naïve or on ARV were included. Of these, pregnant women, patients in whom measurement of ankle blood pressure was difficult as in those with pedal edema or extensive leg ulcers were excluded. Following obtention of written informed consent, a trained investigator carried out a face-to-face interview with each study participant. A structured, pretested questionnaire was used, followed by a physical examination and measurement of resting blood pressures on all four limbs of each study participant and collected $4 \mathrm{~mL}$ of blood for chemical analysis. Patients' medical files were also reviewed for complementary information, such as the stage of HIV disease, and the presence of chronic kidney disease (CKD).

\section{Variables}

Data collected included; sociodemographic information (age, sex, marital status), past medical history (stroke, diabetes mellitus, CKD) cardiovascular risk factors (smoking, alcohol intake, sedentary lifestyle, family history of CVD), HIV disease characteristics (duration since HIV diagnosis, WHO clinical stage, ARV treatment, CD4 cell count $<6$ months and or viral load if available, symptoms suggestive of PAD (intermittent claudication), ${ }^{10}$ anthropometric measurements (weight, height, abdominal circumference), blood pressure (BP) in all four limbs, blood biochemistry (total serum cholesterol, high-density lipoprotein (HDL) cholesterol, low-density lipoprotein (LDL) cholesterol, triglycerides and glucose). Pain or discomfort in the legs that did not fulfill the Edinburg criteria was considered as an atypical pain. ${ }^{11}$

\section{BP, Doppler procedure and measurement of $A B I$}

Blood pressures were measured using a Spengler aneroid sphygmomanometer and appropriate cuff size by the trained investigator after the patient had rested for 10 minutes, in a calm room at a room temperature of $22^{\circ} \mathrm{C} \pm 1{ }^{\circ} \mathrm{C}$.

Brachial BPs in both arms were taken according to standard practice, with the patient in the supine position. Ankle BPs were taken using the same Spengler sphygmomanometer and a hand-held Doppler apparatus (Smart DOP 45) with a probe frequency of 7-8 MHz. Three measurements were taken for each limb by the same observer. We placed the cuff of the sphygmomanometer just above the malleolus, after applying ultrasound gel and identifying the dorsalis pedis and tibialis posterior arteries using the probe. The cuff was inflated to $20 \mathrm{mmHg}$ above the disappearance of the audible Doppler signal. It was then progressively deflated at $2 \mathrm{mmHg}$ per second until the reappearance of the Doppler signal. This was registered as the systolic blood pressure (SBP) at the ankle. The average of three measures was retained. The ABI was calculated as the ratio of ankle SBP to the brachial SBP [Right $\mathrm{ABI}=$ ratio of the right ankle systolic pressure (posterior tibial or dorsalis pedis)/right brachial systolic pressure). Left $\mathrm{ABI}=$ ratio of the left ankle systolic pressure (posterior tibial or dorsalis pedis)/left brachial systolic pressure.

Participants' body weight was measured in light clothing with no shoes using a Medisina ${ }^{\circledR}$ scale balance to the nearest $0.5 \mathrm{~kg}$. Height was taken with no shoes using a stadiometer to the nearest $0.1 \mathrm{~cm}$. We calculated the body mass index (BMI) as: weight $(\mathrm{kg}) /$ height $^{2}\left(\mathrm{~m}^{2}\right)$. Abdominal circumference was measured using a measuring tape, with the patients in the upright position, midway between the iliac crest and lowest rib, in the mid-axillary line to the nearest $0.1 \mathrm{~cm}$.

\section{Biochemical measurements}

We measured total serum cholesterol, HDL cholesterol, LDL cholesterol and triglycerides after 8 hours of fasting, using enzymatic methods with an automate (Cobas C311 Roche). 
We measured the capillary blood glucose using a glucometer (OneTouch Ultra2).

\section{Working definitions}

PAD was defined as an $\mathrm{ABI}<0.9$ and vascular calcifications (incompressible arteries) as an $\mathrm{ABI}>1.3$. An ABI: 0.9-1.3 was normal. ${ }^{3}$ For the severity of PAD, an ABI: $0.7-0.9$ was compensated, an ABI: $0.5-0.7$ was decompensated, and an ABI $<0.5$ was considered as the presence of critical ischemia. ${ }^{12} \mathrm{We}$ defined hypertension according to the seventh Joint National Committee (JNC 7) as an SBP $\geq 140 \mathrm{mmHg}$ and or diastolic blood pressure (DBP) $\geq 90 \mathrm{mmHg}$, or a patient on blood pressure lowering medicine. We defined diabetes according to the WHO as a fasting blood sugar $>1.26 \mathrm{~g} / \mathrm{L}(7 \mathrm{mmol} / \mathrm{L})$ on two separate measurements 1 week apart, or a patient on anti-diabetic agents. Sedentary was a lack of regular physical exercise (30 minutes three times weekly). We defined normal lipid profile according to NCEP ATP III: normal total cholesterol $<2 \mathrm{~g} / \mathrm{L}$, LDL cholesterol $<1 \mathrm{~g} / \mathrm{L}, \mathrm{HDL}$ cholesterol $>0.4 \mathrm{~g} / \mathrm{L}$ for males and $>0.5 \mathrm{~g} / \mathrm{L}$ for females and triglycerides $<1.5 \mathrm{~g} / \mathrm{L}$. BMI was defined according to WHO-underweight: BMI $<18.5 \mathrm{~kg} / \mathrm{m}^{2}$, normal weight: BMI $18.5-24.9 \mathrm{~kg} / \mathrm{m}^{2}$, overweight: BMI $25-29.9 \mathrm{~kg} / \mathrm{m}^{2}$ and obesity: BMI $\geq 30 \mathrm{~kg} / \mathrm{m}^{2}$. Abdominal obesity was a waist circumference $>80 \mathrm{~cm}$ in females and $94 \mathrm{~cm}$ in males. We defined metabolic syndrome according to the International Diabetes Federation (IDF 2005) as the constellation of at least three abnormalities-abdominal obesity (abdominal circumference $>94 \mathrm{~cm}$ in males and $>80 \mathrm{~cm}$ in females), raised blood pressure (SBP $\geq 130 \mathrm{mmHg}$ and or DBP $\geq 85 \mathrm{mmHg}$ ), fasting blood glucose $\geq 100 \mathrm{mg} / \mathrm{dL}$, triglycerides $\geq 1.5 \mathrm{~g} / \mathrm{L}$ and HDL cholesterol $<0.4 \mathrm{~g} /$ Lin males and $<0.5 \mathrm{~g} / \mathrm{L}$ in females. Advanced HIV disease was used for participants with WHO clinical stages III and IV. We defined CKD as persistent renal lesion or dysfunction for at least 3 months.

\section{Sample size consideration}

For this study, we considered a convenient sample of all consenting patients who fulfilled the inclusion criteria during the study period.

\section{Statistical analysis}

Data are presented as mean \pm SD for quantitative data and counts (with percentages in brackets) for qualitative data. Comparison between male and female have been performed using chi-squared and Fisher's exact tests for qualitative data where statistically applicable and Student's $t$-test for quantitative data. Comparison of quantitative data between low, normal, and high ABI patients has been performed using Kruskall-Wallis test. To determine factors associated with PAD, we performed a multivariable logistic regression. Crudes ORs have been calculated and adjusted for age, gender and ARV treatment. Differences were considered significant for $P<0.05$. All statistics have been performed using the software IBM SPSS 20 (SSPS Inc, Chicago, IL, USA) while boxplots have been drawn using the GrapheR package of $\mathrm{R}$ software (Version 3.0.1).

\section{Ethical statement}

For this study, we obtained ethical clearance from the Institutional Ethical Board of the University of Douala, and the administrative authorization of the Douala General Hospital. We carried out this study according to the Declaration of Helsinki. We report this work according to Strengthening the Reporting of Observational Studies in Epidemiology (STROBE) guidelines.

\section{Results}

A total of 144 patients with HIV were included in this study, of which $72.2 \%$ were females. The mean age was $46 \pm 9$ years, most of the participants were older than 40 years and $42.4 \%$ were single.

Table 1 shows the sociodemographic, anthropometric and bioclinical parameters of the study participants. Data are compared between male and female. A past medical history of stroke, diabetes mellitus, and CKD were found in $2.8 \%$, $3.5 \%$, and $4.9 \%$, respectively, of the study population. All six smokers were male. Sedentary lifestyle was frequent in our population $(56.9 \%)$, and was higher among females (63\%) than males (40\%), $P=0.018$. There was a family history of CVD (first degree) in $36.8 \%$ of participants. Among bioclinical parameters, hypertension and lipid disorders were not different in males and females, whereas obesity, abdominal obesity, and HDL cholesterol were significantly higher in females than that in males $(P=0.005, P=0.0004$, and $P=0.016$, respectively).

Table 2 depicts the HIV characteristics of the study population. The mean duration from HIV diagnosis was $89 \pm 57$ months and $88.9 \%$ of participants were on ARV with a mean treatment duration of $87 \pm 59$ months. The nadir CD4+ T lymphocytes count was $207 \pm 155$ cells $/ \mathrm{mm}^{3}$, whereas the current CD4+ T lymphocytes count was $451 \pm 306$ cells $/ \mathrm{mm}^{3}$. Of which, $6.9 \%$ of patients were in stage III or IV of the disease (WHO classification).

Table 3 shows the classification of ABI by sex, according to the severity, symptoms, and ARV treatment. The prevalence of PAD in the population was $6.9 \%$ (95\% CI: 3.4-12.4), 
Table I Baseline characteristics of study participants by sex

\begin{tabular}{|c|c|c|c|c|}
\hline Variable & All $(N=144)$ & Female $(n=104)$ & Male $(n=40)$ & $P$-value \\
\hline \multicolumn{5}{|l|}{ Age (years) } \\
\hline Age $\pm S D$ & $46 \pm 9$ & $45 \pm 9$ & $47 \pm 9$ & 0.2 \\
\hline $20-29$ & $5(3.5)$ & $4(3.8)$ & I (2.5) & \\
\hline $30-39$ & $37(25.7)$ & $29(27.9)$ & $8(20.0)$ & \\
\hline $40-50$ & $53(36.8)$ & $38(36.5)$ & $15(37.5)$ & \\
\hline $5 I-60$ & $49(34.0)$ & $33(31.7)$ & $16(40.0)$ & 0.6 \\
\hline \multicolumn{5}{|l|}{ Marital status (\%) } \\
\hline Single & $61(42.4)$ & $43(41.3)$ & $18(45.0)$ & \\
\hline Divorced & $8(5.6)$ & $4(3.8)$ & $4(10.0)$ & \\
\hline Married & $48(33.3)$ & $31(29.8)$ & $17(42.5)$ & \\
\hline Widowed & $27(18.8)$ & $26(25.0)$ & $\mathrm{I}(2.5)$ & 0.23 \\
\hline \multicolumn{5}{|l|}{ Past history } \\
\hline Stroke (\%) & $4(2.8)$ & $3(2.9)$ & $\mathrm{I}(2.5)$ & 0.9 \\
\hline Diabetes mellitus (\%) & $5(3.5)$ & $3(2.9)$ & $2(5.0)$ & 0.9 \\
\hline CKD (\%) & $7(4.9)$ & $4(3.8)$ & $3(7.5)$ & 0.6 \\
\hline Smoking (\%) & $6(4.2)$ & 0 & $6(15.0)$ & $<0.0001$ \\
\hline Alcohol (\%) & $21(14.6)$ & II (10.6) & $10(25.0)$ & 0.053 \\
\hline Sedentary lifestyle (\%) & $82(56.9)$ & $66(63.5)$ & $16(40.0)$ & 0.018 \\
\hline Family history of CVD (\%) & $53(36.8)$ & $38(36.5)$ & $15(37.5)$ & 0.9 \\
\hline \multicolumn{5}{|l|}{ Bio-clinical parameters } \\
\hline Systolic BP (mmHg) & $117 \pm 21$ & $|16 \pm 2|$ & $120 \pm 23$ & 0.3 \\
\hline Diastolic BP (mmHg) & $69 \pm 14$ & $69 \pm 14$ & $70 \pm 15$ & 0.7 \\
\hline Hypertension (\%) & $29(20.1)$ & $24(23.1)$ & $5(12.5)$ & 0.23 \\
\hline BMI $\left(\mathrm{kg} / \mathrm{m}^{2}\right)$ & $26.5 \pm 5.4$ & $26.8 \pm 5.5$ & $25.5 \pm 5.2$ & 0.195 \\
\hline Obesity (\%) & $36(25.0)$ & $33(31.7)$ & $3(7.5)$ & 0.005 \\
\hline Abdominal obesity (\%) & $50(34.7)$ & $46(44.2)$ & $4(10.0)$ & 0.004 \\
\hline Blood glucose (g/L) & $0.92 \pm 0.13$ & $0.91 \pm 0.12$ & $0.95 \pm 0.14$ & 0.17 \\
\hline Total cholesterol $(\mathrm{g} / \mathrm{dL})$ & $1.95 \pm 0.48$ & $2.0 I \pm 0.5 \mathrm{I}$ & $|.84 \pm 0.4|$ & 0.113 \\
\hline HDL cholesterol $(\mathrm{g} / \mathrm{dL})$ & $0.58 \pm 0.20$ & $0.61 \pm 0.20$ & $0.50 \pm 0.21$ & 0.016 \\
\hline Triglycerides (g/dL) & $0.91 \pm 0.42$ & $0.87 \pm 0.43$ & $0.97 \pm 0.49$ & 0.285 \\
\hline LDL cholesterol (g/dL) & $|| 7 \pm 0.4 \mid$. & $1.20 \pm 0.44$ & $1.12 \pm 0.35$ & 0.391 \\
\hline Lipid disorders (\%) & $44(30.6)$ & $29(27.9)$ & $15(37.5)$ & 0.3 \\
\hline
\end{tabular}

Abbreviations: BMI, body mass index; BP, blood pressure; CKD, chronic kidney disease; CVD, cardiovascular disease; HDL, high-density lipoproteins; LDL, low-density lipoproteins.

Table 2 Characteristics of HIV infection in participants

\begin{tabular}{|c|c|c|c|c|}
\hline Variable & All $(N=144)$ & Female $(n=104)$ & Male $(n=40)$ & $P$-value \\
\hline Time since infection (months) & $89 \pm 57$ & $93 \pm 60$ & $79 \pm 48$ & 0.192 \\
\hline On ARV (\%) & I $28(88.9)$ & $94(90.4)$ & $34(85.0)$ & 0.3 \\
\hline Time since ARV (months) & $87 \pm 59$ & $86 \pm 51$ & $89 \pm 79$ & 0.804 \\
\hline Nadir CD4+ T lymphocytes (cells $/ \mathrm{mm}^{3}$ ) & $207 \pm 155$ & $205 \pm 157$ & $211 \pm 154$ & 0.860 \\
\hline CD4+ T lymphocytes (cells/mm³) & $45 \mathrm{I} \pm 306$ & $480 \pm 313$ & $373 \pm 284$ & 0.091 \\
\hline Detectable viral load (\%) & $78(54.2)$ & $57(54.8)$ & $21(52.5)$ & 0.8 \\
\hline WHO stages III and IV (\%) & $10(6.9)$ & $6(5.8)$ & $4(10.0)$ & 0.3 \\
\hline
\end{tabular}

Abbreviation: ARV, antiretroviral treatment.

whereas those with high ABI was 9\% (95\% CI: 4.9-14.9). Among those with low ABI (PAD), 60\% were symptomatic and $60 \%$ were on ARV therapy. No significant difference was observed between the sexes.

Table 4 shows the comparison of variables of the study participants according to ABI. Patients with low ABI were younger $(P=0.002)$, and fewer were on ARV $(P=0.026)$ compared to those with normal and high ABI. There were no differences as regards cardiovascular risk factors in the different ABI categories.

Table 5 shows the crude and adjusted ORs of factors associated to PAD. Only ARV treatment and WHO stages III 
Table 3 Classification of $A B I$, symptoms and ARV by sex among study participants

\begin{tabular}{|c|c|c|c|c|}
\hline Variable & All $(N=144)$ & Female $(n=104)$ & Male $(n=40)$ & $P$-value \\
\hline Low ABI (PAD): $<0.7-0.9$ & $10(6.9)$ & $7(6.7)$ & $3(7.5)$ & 0.5 \\
\hline Normal ABI: 0.9-I.3 & I2I (84.0) & 89 (85.6) & $32(80.0)$ & 0.8 \\
\hline High $A B I>1.3$ & $13(9.0)$ & $8(7.7)$ & $5(12.5)$ & 0.5 \\
\hline Asymptomatic low $\mathrm{ABI}<0.9$ & $4(40.0)$ & $2(28.6)$ & $2(66.7)$ & - \\
\hline Symptomatic low $\mathrm{ABI}<0.9$ & $6(60)$ & $5(7 I .5)$ & $\mathrm{I}(33.3)$ & 0.6 \\
\hline Untreated with low $\mathrm{ABI}<0.9$ & $4(40.0)$ & $3(42.9)$ & I (33.3) & - \\
\hline Treated with low $\mathrm{ABI}<0.9$ & $6(60.0)$ & $4(57.1)$ & $2(66.7)$ & 0.6 \\
\hline
\end{tabular}

Abbreviations: $A B I$, ankle brachial index; $A R V$, antiretroviral treatment; $P A D$, peripheral artery disease.

Table 4 Comparison of different variables of study participants according to $A B I$

\begin{tabular}{|c|c|c|c|c|}
\hline Variable & $\begin{array}{l}A B I<0.9 \\
n=10\end{array}$ & $\begin{array}{l}\text { ABI: } 0.9-1.3 \\
n=|2|\end{array}$ & $\begin{array}{l}A B \mid>1.3 \\
n=13\end{array}$ & $P$-value \\
\hline Age (years) & $42 \pm 11$ & $45 \pm 9$ & $54 \pm 6$ & 0.002 \\
\hline Female gender (\%) & $3(37.5)$ & $32(26)$ & $5(38.5)$ & 0.5 \\
\hline Time since infection (years) & $62 \pm 57$ & $89 \pm 57$ & $106 \pm 50$ & 0.2 \\
\hline ARV (\%) & $5(62.5)$ & $110(89.4)$ & $13(100)$ & 0.026 \\
\hline Time since ARV (years) & $87 \pm 40$ & $87 \pm 62$ & $93 \pm 39$ & 0.2 \\
\hline Nadir CD4+ T lymphocytes (cells $/ \mathrm{mm}^{3}$ ) & $208 \pm 247$ & $212 \pm 153$ & $164 \pm 117$ & 0.3 \\
\hline CD4+ T lymphocytes (cells $/ \mathrm{mm}^{3}$ ) & $398 \pm 259$ & $452 \pm 314$ & $463 \pm 244$ & 0.3 \\
\hline WHO stages III and IV (\%) & $3(37.5)$ & $7(5.7)$ & 0 & 0.043 \\
\hline Hypertension (\%) & $2(25.0)$ & $22(17.9)$ & $5(38.5)$ & 0.2 \\
\hline Obesity (\%) & 0 & $34(27.6)$ & $2(15.4)$ & 0.15 \\
\hline Metabolic syndrome (\%) & $I(12.5)$ & $10(8.1)$ & I (7.7) & 0.9 \\
\hline Smoking (\%) & 0 & I (7.7) & $5(4.1)$ & 0.6 \\
\hline Alcohol (\%) & $I(12.5)$ & $3(23.1)$ & $17(13.8)$ & 0.6 \\
\hline Sedentary lifestyle (\%) & $6(75.0)$ & $5(38.5)$ & 71 (57.7) & 0.2 \\
\hline Lipid disorders (\%) & $4(50.0)$ & $37(30.1)$ & $3(23.1)$ & 0.4 \\
\hline Total cholesterol (g/dL) & $2.25 \pm 0.31$ & $1.94 \pm 0.48$ & $1.89 \pm 0.53$ & 0.5 \\
\hline HDL cholesterol $(g / d L)$ & $0.54 \pm 0.34$ & $0.58 \pm 0.20$ & $0.59 \pm 0.20$ & 0.4 \\
\hline Triglycerides (g/dL) & $1.10 \pm 0.10$ & $0.89 \pm 0.45$ & $1.05 \pm 0.68$ & 0.2 \\
\hline LDL cholesterol (g/dL) & $1.42 \pm 0.50$ & $1.16 \pm 0.40$ & $1.10 \pm 0.40$ & 0.3 \\
\hline
\end{tabular}

Abbreviations: $A B I$, ankle-brachial index; $A R V$, antiretroviral treatment; $B M I$, body mass index; $B P$, blood pressure; $C V D$, cardiovascular disease; HDL, high-density lipoproteins; LDL, low-density lipoproteins; PAD, peripheral artery disease.

and IV were significantly associated with PAD. Crude OR shows that ARV treatment reduced the risk of PAD (OR: 0.15 [95\% CI: 0.04-0.6] $P=0.007$ ), whereas WHO stage III or IV had increased risk of PAD (OR: 8.64 [95\% CI: 1.78-42.03], $P=0.008)$. After adjustment for age, sex and ARV treatment, the association remained significant.

Figure 1 shows the comparison of $\mathrm{ABI}$ between males and females. The mean ABI in the population was $1.12 \pm 0.17$ and $1.07 \pm 0.11$, respectively, on the left and right legs. ABI was not significantly different between males and females in the left leg (1.16 \pm 0.26 and $1.11 \pm 0.11$, respectively, $P=0.069)$ and in the right leg $(1.09 \pm 0.12$ and $1.07 \pm 0.10$, respectively, $P=0.25)$.

\section{Discussion}

This study was aimed at studying PAD in HIV-infected individuals attending the DGH HIV treatment center. The prevalence of low ABI, indicative of PAD, in the study population, was $6.9 \%$. Advanced HIV disease was associated with PAD while being on ARV reduced the likelihood of PAD.

Generally, there is an increasing prevalence of cardiovascular diseases in this setting and the medical literature attests to that. However, of all the different etiologies, PAD has received less attention so data are sparse. There are only a few studies that have been carried out in the general population and much less so for PAD in HIV-positive patients.

It has been shown that PAD occurs more frequently in HIV-positive patients than in the general population. ${ }^{13-16}$ A prevalence of $6.9 \%$ as found in this study is low for a population expected to have high cardiovascular risk factors and increased cardiovascular morbidity and mortality. This finding is much lower than what was found in two studies in sub-Saharan Africa on HIV-negative subjects, 
Table 5 Crude and adjusted ORs of factors associated with PAD

\begin{tabular}{|c|c|c|c|c|}
\hline \multirow[t]{2}{*}{ Variable } & \multicolumn{2}{|l|}{ Univariable } & \multicolumn{2}{|l|}{ Multivariable } \\
\hline & OR $(95 \% \mathrm{Cl})$ & $P$-value & $\mathrm{aOR}^{\mathrm{a}}(95 \% \mathrm{Cl})$ & $P$-value \\
\hline Age (years) & $1.05(0.98-1.13)$ & 0.14 & $0.98(0.91-1.06)$ & 0.62 \\
\hline Female gender & I. $12(0.28-4.58)$ & 0.87 & $0.66(0.14-3.1)$ & 0.6 \\
\hline Family history of CVD (\%) & $1.39(0.34-5.62)$ & 0.64 & $1.06(0.23-4.92)$ & 0.94 \\
\hline Alcohol (\%) & I.5I (0.3-7.67) & 0.62 & $0.7(0.08-6.39)$ & 0.75 \\
\hline Sedentary lifestyle & $\mathrm{I} .84(0.45-7.4 \mathrm{I})$ & 0.39 & $2.27(0.43-11.98)$ & 0.33 \\
\hline Lipid disorders & $0.64(0.17-2.35)$ & 0.9 & $0.69(0.17-2.75)$ & 0.6 \\
\hline Total cholesterol (g/dL) & $0.37(0.05-2.57)$ & 0.32 & $3.09(0.33-29.04)$ & 0.32 \\
\hline HDL cholesterol $(\mathrm{g} / \mathrm{dL})$ & $5.28(0.52-53.08)$ & 0.16 & $0.33(0.03-3.97)$ & 0.38 \\
\hline Triglycerides (g/dL) & $1.36(0.11-16.75)$ & 0.81 & $0.54(0.03-10.33)$ & 0.68 \\
\hline LDL cholesterol $(\mathrm{g} / \mathrm{dL})$ & $0.69(0.08-6.01)$ & 0.74 & $1.43(0.14-|4.7|)$ & 0.76 \\
\hline Time since infection (years) & I.01 (0.99-I.02) & 0.28 & I (0.98-1.02) & 0.8 \\
\hline ARV (\%) & $0.15(0.04-0.6)$ & 0.007 & $0.18(0.04-0.82)$ & 0.034 \\
\hline Duration on ARV (years) & I (0.99-1.0I) & 0.47 & $\mathrm{I}(0.98-1.0 \mathrm{I})$ & 0.9 \\
\hline CD4 initial & I (0.99-I.0I) & 0.63 & I (0.99-I.008) & 0.85 \\
\hline CD4 recent & I (0.99-I.003) & 0.96 & I (0.99-I.002) & 0.9 \\
\hline WHO stages III or IV (\%) & $8.64(1.78-42.03)$ & 0.008 & II.I (2.19-55.92) & 0.004 \\
\hline BMI $\left(\mathrm{kg} / \mathrm{m}^{2}\right)$ & $0.92(0.83-1.01)$ & 0.08 & $0.96(0.8 I-I .12)$ & 0.58 \\
\hline Obesity (\%) & $3.18(0.39-26.0)$ & 0.2 & $2.6 I(0.3 I-22 . I)$ & 0.37 \\
\hline Metabolic syndrome (\%) & $1.24(0.11-3.92)$ & 0.84 & $0.62(0.06-6.09)$ & 0.68 \\
\hline
\end{tabular}

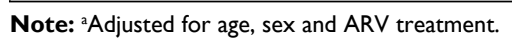

Abbreviations: ARV, antiretroviral treatment; BMI, body mass index; CVD, cardiovascular disease; HDL, high-density lipoproteins; LDL, low-density lipoproteins; PAD, peripheral artery disease.

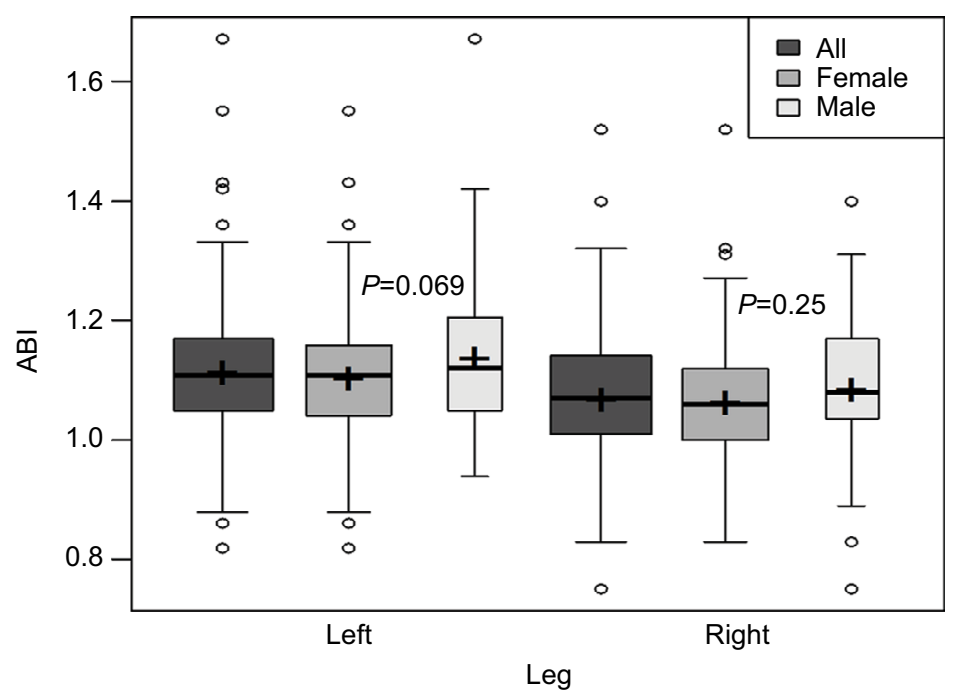

Figure I Comparison of $A B I$ between males and females. The midline of the boxes represents the median and the lower and upper margins represent the 25 th and 75 th percentiles, respectively.

Notes: The lower and upper ends represent the minimum and maximum values, respectively, and the central dot represents the mean. It should be noted that the $P$-values denote the level of significance between males and females and does not involve the "All".

Abbreviation: $A B I$, ankle-brachial index.

$16.7 \%$ and $25.9 \%$ in Cameroon and Benin, respectively. ${ }^{17,18}$ In both studies, participants all had cardiovascular risk factors. Studies on PAD in HIV-positive patients in subSaharan Africa were not found by us in the literature. There are, however, contradictory observations on PAD in this population from various studies. Some European and American authors found the prevalence of PAD in 1 HIV positive patients ranging from $6.3 \%$ to $9.8 \%^{15,19}$ and even lower prevalence below $2 \%$ by others. ${ }^{20,21}$ Contrary to this, higher prevalence (over 10\%) have also been found. ${ }^{22}$ From the data presented in this study, the fact that there was a low proportion of participants with $\mathrm{CV}$ risk factors such as smoking, diabetes and dyslipidemias may have contributed to the low prevalence. 
Advanced HIV disease (WHO stages III and IV) was found to be associated with a low ABI. This has been previously reported..$^{19}$ A possible explanation could be that in the course of opportunistic infections seen in advanced HIV disease, there is an accompanying intense inflammation..$^{19}$ Caution should be exercised using the WHO classification, as it might not reflect low CD4 lymphocytes and high viremia. High viremia might be associated with intense inflammation with a fair clinical status.

The finding that being on ARV seemed to have reduced the likelihood of PAD is a paradoxical finding as combination ARV especially protease inhibitors, has been shown to be associated with dyslipidemia, lipodystrophy, and impaired glucose tolerance, all associated with the development of premature atherosclerosis. ${ }^{15,23}$ On the other hand, if one considers the fact that HIV itself causes vascular disease either by a direct effect on vascular or perivascular tissue or indirectly via immune complex-mediated mechanisms, ARV may have an important role in controlling PAD disease progression.

We did not find any association between PAD and the traditional CV risk factors as reported by some authors. ${ }^{15,22}$ This also may be explained by the low prevalence of those factors (smoking, diabetes, dyslipidemia) in the study participants as was reported by Olalla et a ${ }^{13}$.

There were a number of limitations to this study. The presence of a control group (HIV negative) would have improved our understanding of this pathology in a setting where no previous studies were available. The relatively small sample size made it difficult to interpret some of our findings especially the small numbers who were not on ARV as this may have better clarified our findings of being on ARV as protective of PAD. Also, statistical significance could not be attained for some variables probably due to the sample size, thus limiting multiple testing. There is a need for similar studies in our setting to enable pooling of the data and have a clearer picture. There was no possibility of comparing our results with others in this setting as we did not find them in the literature. Lastly, this was a single center study in a tertiary hospital, therefore our findings cannot be generalized.

\section{Conclusion}

We found a low prevalence of PAD in HIV-infected patients attending a treatment center in a tertiary hospital in Cameroon. On the basis of this finding, routine screening for PAD may not be necessary in this group of patients. Instead screening should follow guidelines by the $\mathrm{AHA} / \mathrm{ACC}^{24}$ on an individual basis and monitoring potential risk factors.

\section{Acknowledgments}

We thank the day support staff of the Douala General Hospital for assisting with patient care and comfort. We also thank the participants for taking part in this study.

\section{Author contributions}

Conception: FK, YM, BH, and HL. Design: FK, YM, BH, MSD, GI, JPNM, and HL. Data collection: FK, YM, BH, FS, CK, GI, JPNM, MSD, and HL. Data analysis and interpretation: FK, YM, BH, FS, AMJ, MSD and HL. Drafting of manuscript: FK, YM, BH, FS, CK, AMJ, GI, FKL, JKF, and JPNM. Critical review of the final draft: MSD and HL. All authors contributed toward data analysis, drafting and critically revising the paper, gave final approval of the version to be published and agree to be accountable for all aspects of the work.

\section{Disclosure}

The authors report no conflicts of interest in this work.

\section{References}

1. World Health Organization (WHO). Cardiovascula disease. January 2015. Available from: http://www.who.int/mediacentre/factsheets/fs317/ fr/. Accessed November 1, 2015.

2. Ticolat R, Bertrand E, Agboton H, Barabe P, Diallo B, Monkam Y. Epidémiologie de l'artériopathie chronique oblitérante des membres inférieurs chez les patients porteurs d'hypertension artérielle au CHU de Cotonou [Epidemiological findings concerning the lower limbarteritis in black African: retrospective study in 72 cases (ARTERAFRIC)]. Trop Cardiol. 1991;135:45-52. French.

3. Haute Autorité de Santé. Prise en charge de l'artériopathie chronique oblitéranteathéroscléreuse des membres inférieurs (indications médicamenteuses, de revascularisation et de rééducation), Avril 2006. Available from: http://www.has-sante.fr/portail/upload/docs/application/pdf/ AOMI_recos.pdf.Consulté le. Accessed October 26, 2015.

4. Sampson UK, Fowkes FG, McDermott MM, et al. Global and regional burden of death and disability from peripheral artery disease: 21 world regions, 1990 to 2010. Glob Heart. 2014;9(1):e21.145-e21.158.

5. Grunfeld C, Delaney JA, Wanke C, et al. Preclinical atherosclerosis due to HIV infection: carotid intima-medial thickness measurements from the FRAM study. AIDS. 2009;23(14):1841-1849.

6. UNAIDS. Information sheet 2014. Available from: http://www.unaids org/fr/resources/campaigns/2014/2014gapreport/factsheet. Accessed November 2, 2015.

7. UNAIDS. HIV and AIDS Estimations (2014). Available from: http:// www.unaids.org/fr/regionscountries/countries/cameroun. Accessed November 2, 2015.

8. Capeau J, Caron M, Vigouroux C. Les lipodystrophies secondaires aux traitements antirétroviraux de l'infection par le VIH [Lipodystrophy Secondary to antiretroviral therapy for HIV infection]. Médecine/sciences. 2006;22(5):531-536.

9. Statistique Indela. Caractéristiques de la population. [National Institute of Statistics. Characteristics of the population] Annuaire Statistique du Cameroun. 2015:54-63.

10. Savès M, Raffi F, Capeau J, et al. Factors related to lipodystrophy and metabolic alterations in patients with human immunodeficiency virus infection receiving highly active antiretroviral therapy. Clin Infect Dis. 2002;34(10):1396-1405. 
11. Bernstein EF, Fronek A. Current status of noninvasive tests in the diagnosis of peripheral arterial disease. Surg Clin North Am. 1982;62(3):473-487.

12. Benhamou $Y$, Lévesque $H$. Quelle technique utilisez-vous pour la mesure de l'index systolique? [What technique do you use to measure the ankle brachial index]. SVT. 2006;18(5):278-281. French.

13. Olalla J, Salas D, del Arco A, et al. Ankle-branch index and HIV: the role of antiretrovirals. HIV Med. 2009;10(1):1-5.

14. Kwiatkowska W, Knysz B, Arczyńska K, et al. Peripheral arterial disease and ankle-brachial index abnormalities in young and middleaged HIV-positive patients in lower Silesia, Poland. PLoS One. 2014;9(12):e113857.

15. Periard D, Cavassini M, Taffé $P$, et al. High prevalence of peripheral arterial disease in HIV-infected persons. Clin Infect Dis. 2008;46(5):761-767.

16. Palacios R, Alonso I, Hidalgo A, et al. Peripheral arterial disease in HIV patients older than 50 years of age. AIDS Res Hum Retroviruses. 2008;24(8):1043-1046.

17. Menanga AP, Kougang NC, Ahmadou MJ, Mfangam BM, Noubiap JJ. Patterns of cardiovascular disease in a group of HIV-infected adults in Yaoundé, Cameroon. Cardiovasc Diagn Ther. 2015;5(6).

18. Houenassi DM, Houehanou C, Tchabi Y. Epidémiologie de l'artéripathie chronique oblitérante des membres inférieurs chez les patients porteurs d'hypertension artérielle au CHU de Cotonou [Epidemiology of peripheral artery disease of the lower limbs in patients with hypertension in CHU of Cotonou]. Trop Cardiol. 2012(135).
19. Canalejo E, Cabello N, Perales I, Allodi S, Sánchez-Purificación A. Enfermedad arterial periférica asintomática estimada mediante el índice tobillo-brazo en pacientes con infección por el VIH: prevalencia $\mathrm{y}$ factores de riesgo asociados [Asymptomatic peripheral arterial disease estimated by the ankle-brachial index in patients with HIV infection. Prevalence and associated risk factors]. Enfermedades Infecc Microbiol Clínica. 2011;29(9):672-678.

20. Sharma A, Holman S, Pitts R, Minkoff HL, Dehovitz JA, Lazar J. Peripheral arterial disease in HIV-infected and uninfected women. HIV Med. 2007;8(8):555-560.

21. Knudsen A, Malmberg CAE, Kjær A, Lebech AM. Low prevalence of peripheral arterial disease in a cross-sectional study of Danish HIVinfected patients. Infect Dis. 2015;47(11):776-782.

22. Qaqa AY, Debari VA, El-Kersh K, et al. Epidemiologic aspects of abnormal ankle-brachial index in the HIV infected population. Int Angiol. 2012;31(3):227-233.

23. Johnsen S, Dolan SE, Fitch KV, et al. Carotid intimal medial thickness in human immunodeficiency virus-infected women: effects of protease inhibitor use, cardiac risk factors, and the metabolic syndrome. J Clin Endocrinol Metab. 2006;91(12):4916-4924.

24. Nishimura RA, Otto CM, Bonow RO. AHA/ACC Focused Update of the 2014 AHA/ACC Guideline for the Management of Patients with Valvular Heart Disease: A Report of the American College of Cardiology/American Heart Association Task Force on Clinical Practice Guidelines. Circulation. 2017;135(25):e1159-e1195.
Vascular Health and Risk Management

\section{Publish your work in this journal}

Vascular Health and Risk Management is an international, peerreviewed journal of therapeutics and risk management, focusing on concise rapid reporting of clinical studies on the processes involved in the maintenance of vascular health; the monitoring, prevention and treatment of vascular disease and its sequelae; and the involvement of

\section{Dovepress}

metabolic disorders, particularly diabetes. This journal is indexed on PubMed Central and MedLine. The manuscript management system is completely online and includes a very quick and fair peer-review system, which is all easy to use. Visit http://www.dovepress.com/ testimonials.php to read real quotes from published authors. 